\title{
LIQUID SHOOT CULTURE OF SALVIA OFFICINALIS L. FOR MICROPROPAGATION AND PRODUCTION OF ANTIOXIDANT COMPOUNDS; EFFECT OF TRIACONTANOL
}

\author{
IZABELA GRZEGORCZYK, HALINA WYSOKIŃSKA \\ Department of Biology and Pharmaceutical Botany, Medical University in Łódź \\ Muszyńskiego 1, 90-151 Łódź, Poland \\ e-mail: botanika@pharm.am.lodz.pl
}

(Received: April 3, 2007. Accepted: September 12, 2007)

\begin{abstract}
Liquid shoot culture of Salvia officinalis L. in MS medium containing IAA $\left(0.1 \mathrm{mg} \mathrm{l}^{-1}\right)$ and BAP $\left(0.45 \mathrm{mg} \mathrm{l}^{-1}\right)$ was developed and evaluated in relation to shoot multiplication and antioxidant compound (carnosic acid, carnosol and rosmarinic acid) accumulation. In the liquid medium, on average, 3 new shoots per explant (shoot tip) were obtained within 3 weeks. The shoots produced $8.2 \pm 0.02 \mathrm{mg}$ of diterpenoids and $31.2 \pm 0.29 \mathrm{mg}$ of rosmarinic acid per gram of dry weight. Shoot proliferation and diterpenoid content increased when triacontanol $(5,10$ or 20 $\mu \mathrm{g}^{-1}$ ) was added to the liquid medium. In optimum conditions (at $20 \mu \mathrm{g}^{-1}$ TRIA) almost 7 shoots were formed per explant after 3 weeks. An increase in diterpenoid production (expressed as the sum of carnosol and carnosic acid) ranged from $30 \%$ to $50 \%$ and dependended on triacontanol concentration tested. The level of diterpenoids in triacontanol-treated shoots was similar to the content of compounds in commercial herbal product (dried leaves of S. officinalis) (10-12 $\mathrm{mg} \mathrm{g}^{-1} \mathrm{dry} \mathrm{wt}$ ). Triacontanol did not increase rosmarinic acid production, but the content of the phenolic as compound in shoots grown in liquid culture $\left(31 \mathrm{mg} \mathrm{g}^{-1} \mathrm{dry}\right.$ wt) was even 24 times higher compared to samples of dried leaves of $S$. officinalis plants. We also demonstrated that the highest amounts of CA, Car and RA were accumulated in young, top parts of sage shoots. This observation could be useful for improving the selection of material for the extraction of natural antioxidants from S. officinalis.
\end{abstract}

KEY WORDS: antioxidant compounds, liquid shoot culture, Salvia officinalis L., triacontanol.

\section{INTRODUCTION}

Salvia officinalis L. (sage) is an aromatic perennial herb native to Southern Europe and Asia Minor. Among different species of the genus Salvia, S. officinalis is the economically most significant species, widely used in medicine, cosmetology and food industry. This plant is listed in pharmacopoeias of many countries. Leaf extracts of sage show antibacterial, antiviral, anti-inflammatory, hypoglycemic and antihydrotic activities (Farag et al. 1989; Leung 1989; Tada et al. 1994; Essway et al. 1995; Baricevic et al. 2001). Recently, Rau et al. (2006) have reported that the glucose lowering potential of sage and rosemary may be attributed to peroxisome proliferators-activated receptor gamma (PPAR $\gamma$ ) activation by carnosic acid and carnosol. Sage extracts have also revealed very strong scavenging activity of active oxygens and inhibition of lipid peroxidation (Haraguchi et al. 1995). These properties are mainly due to the presence of abietane diterpenoids (especially carnosic acid and carnosol) and caffeic acid derivatives (e.g. rosmarinic acid) (Cuvelier et al. 1994). Moreover, carnosol and carnosic acid show apoptitic and antitumor effects (Huang et al. 1994; Offord et al. 1995).
We have previously described micropropagation of $S$. officinalis using shoot tips grown on agar-solidified medium and showed that multiple shoots and in vitro regenerated plants were able to synthesize carnosol (Car), carnosic acid (CA) and rosmarinic acid (RA) (Grzegorczyk et al. 2005 and 2006). In vitro propagation of S. officinalis in solid culture has been also reported by other authors (Olszowska and Furmanowa 1992; Santos-Gomes et al. 2002). However, no data were found about liquid culture system for sage shoot multiplication. The establishment of culture in liquid media has several advantages, such as faster growth and multiplication rate (Ascough and Fennell 2004), lack of impurities from agar, dilution of exudates from the explants (Ziv and Halevy 1983), uniform dispersal and better availability of nutrients and growth regulators (Debergh 1983). The liquid system could be useful for increasing the scale of production (towards scaling up for bioreactor study) and cost reduction (agar is one of the most expensive ingredients in the medium). However, to establish the procedure for propagation of plants in a bioreactor, culture conditions should be examined using solid medium and then using liquid medium. For the abovementioned reasons we decided to develop the liquid culture 
of S. officinalis shoots for micropropagation and production of antioxidant compounds i.e. carnosic acid, carnosol and rosmarinic acid. We also used the liquid shoot culture as a model system for the study of the factors, which could stimulate shoot multiplication and production of antioxidant compounds. In this study, triacontanol (TRIA) was chosen as the factor. The choice of TRIA was based on our earlier research with sage shoots cultured on agar medium supplemented with this natural plant growth promoter (Grzegorczyk et al. 2006) and literature reports (Yaseen and Tajuddin 1998; Tantos et al. 1999; Fraternale et al. 2003). For comparison, contents of antioxidant compounds in commercially available samples of sage leaves were presented. Moreover, the detailed analysis of carnosol, carnosic acid and rosmarinic acid distribution in different parts of shoots of micropropagated S. officinalis plants from greenhouse was performed in this study.

\section{MATERIALS AND METHODS}

\section{Establishment of liquid shoot culture}

Shoot tips $(0.5 \mathrm{~cm})$ of multiple shoot culture of $S$. officinalis on MS (Murashige and Skoog 1962) agar (0.7\%) medium supplemented with IAA $\left(0.1 \mathrm{mg} \mathrm{l}^{-1}\right)$ and BAP $(0.45$ $\mathrm{mg}^{-1}$ ) were inoculated into liquid medium of the same composition, but excluding agar. Shaken liquid shoot culture was initiated by placing shoot tips into $300 \mathrm{ml}$ Erlenmeyer flasks containing $25 \mathrm{ml}$ of MS liquid multiplication medium. Two shoot tips were added per flask. The cultures were incubated on a rotary shaker (100 rpm) for 3 weeks. For initiation of static liquid culture, shoot tips were transferred into Magenta vessels $(77 \times 77 \times 97 \mathrm{~mm})$ containing 25 $\mathrm{ml}$ liquid MS medium. Two shoot tips were added per vessel. The liquid media were adjusted to $\mathrm{pH}$ 5.6-5.9 before being sterilized by autoclaving at $121^{\circ} \mathrm{C}$ for $17 \mathrm{~min}$. All cultures were kept at $26 \pm 2^{\circ} \mathrm{C}$ under a $16 \mathrm{~h}$ photoperiod provided by cool white fluorescent lamps (approximately 40 $\mu \mathrm{mol} \mathrm{m} \mathrm{m}^{-2} \mathrm{~s}^{-1}$ ). Only the shoots from static liquid culture were further subcultured every three weeks and used in the experiments described in the work.

\section{Rooting and transplantation}

Shoots that developed in liquid multiplication medium were transferred individually into half strength MS agar $(0.7 \%)$ medium supplemented with IAA $\left(0.1 \mathrm{mg} \mathrm{l}^{-1}\right)$. The shoots were maintained for 4 weeks under the same culture conditions as for shoot multiplication. After this time, the percentage of rooted shoots was recorded. Rooted plantlets (28 in number) were transplanted to pots filled with sterilized mixture of sand, peat and soil $(3: 3: 4 \mathrm{v} / \mathrm{v} / \mathrm{v})$ and grown for 10 weeks in greenhouse conditions to determine the percentage of plants that survived.

\section{Influence of TRIA}

The influence of TRIA on shoot multiplication and production of antioxidant compounds in liquid static culture in Magenta vessel was evaluated by inoculating shoot tips in liquid shoot multiplication media (MS with $0.1 \mathrm{mg} \mathrm{l}^{-1}$ IAA and $0.45 \mathrm{mg} \mathrm{l}^{-1} \mathrm{BAP}$ ) supplemented with 0 (control), 5, 10 or $20 \mu \mathrm{g} \mathrm{1^{-1 }}$ TRIA. TRIA solution was prepared as described in our previous work (Grzegorczyk et al. 2006). After 3 weeks, the number of shoots per explant was determined.
The shoots were weighed at the beginning and the end of the culture cycle ( 3 weeks) and the growth index (GI) was calculated as follows:

$\mathrm{GI}=($ final biomass weight - initial biomass weight $) /$ initial biomass weight.

Five Magenta vessels for each treatment were used, each vessel contained two explants. The experiment was repeated three times.

\section{Extraction and quantitative determination of antioxidant compounds}

For quantitative determination of carnosic acid, carnosol and rosmarinic acid, 3-week-old shoots grown in liquid MS medium containing IAA $\left(0.1 \mathrm{mg} \mathrm{l}^{-1}\right)$, BAP $\left(0.45 \mathrm{mg} \mathrm{l}^{-1}\right)$ and TRIA $\left(0,5,10\right.$ or $\left.20 \mu \mathrm{g} \mathrm{l}^{-1}\right)$ were used. The commercially available samples of sage leaves were used as a material for the comparative analysis. The samples were purchased from Kawon (Krajewice, Poland) and Phytopharm (Dobrzyca, Poland) and they were "representative" of this what consumers use for medicinal purposes. To study the distribution of antioxidant compounds, the sage shoots from 10-week-old micropropagated plants grown in greenhouse were divided into three parts: upper (located at the top of shoot, consisting of the terminal bud and two nodes below the bud with two parts of leaves), internal (with two middle nodes and leaves) and lower (at the base of shoots).

Dried plant materials were extracted with acetone (for $\mathrm{CA}$ and Car analysis) or methanol (for RA analysis). HPLC analysis was performed on a Waters (Milford, USA) Symetry ${ }^{\circledR}$ C 18 column $(4.6 \times 150 \mathrm{~mm}, 3.5 \mu \mathrm{m})$ with $2 \mathrm{~cm}$ guard column. The solvent systems were acetonitrile/0.1\% o-phosphoric acid 65:35 (v/v) and acetonitrile/0.1\% o-phosphoric acid 30:40 (v/v) for diterpenes and RA analysis, respectively. The details of extraction procedure and HPLC analysis were described earlier (Grzegorczyk et al. 2006). The compound concentrations were achieved using calibration curves prepared with standard compounds. Compound contents were expressed as $\mathrm{mg} \mathrm{g}^{-1}$ of dry weight.

Data were recorded as means of three replicates \pm standard error. For TRIA treatment the data were analyzed using U Mann-Whitney test (at a 5\% probability level).

\section{RESULTS AND DISCUSSION}

Shoot tips of $S$. officinalis were incubated in liquid MS medium supplemented with IAA $\left(0.1 \mathrm{mg} \mathrm{l}^{-1}\right)$ and BAP $\left(0.45 \mathrm{mg} \mathrm{l}^{-1}\right)$. This combination of growth regulators was selected on the basis of our earlier experiments with sage shoot culture on agar-solidified medium (Grzegorczyk and Wysokińska 2004). Two types of liquid cultures under static (in Magenta vessels) and agitated (in Erlenmeyer flasks) conditions were used to determine the effect of liquid media on sage shoot proliferation. Our experiments showed that shaken liquid culture was not effective in growth of sage shoot tips; they turned brown and hyperhydricity and necrosis were observed within 3 weeks after the culture initiation. It indicates that the shoots are sensitive to shear stress and/or totally submerged within liquid medium. Based on this result the static liquid culture in Magenta vessels was chosen for subsequent experiments. In that culture, the shoots were only partially submerged in liquid medium (Fig. 1) and no hyperhydricity symptoms were obse- 


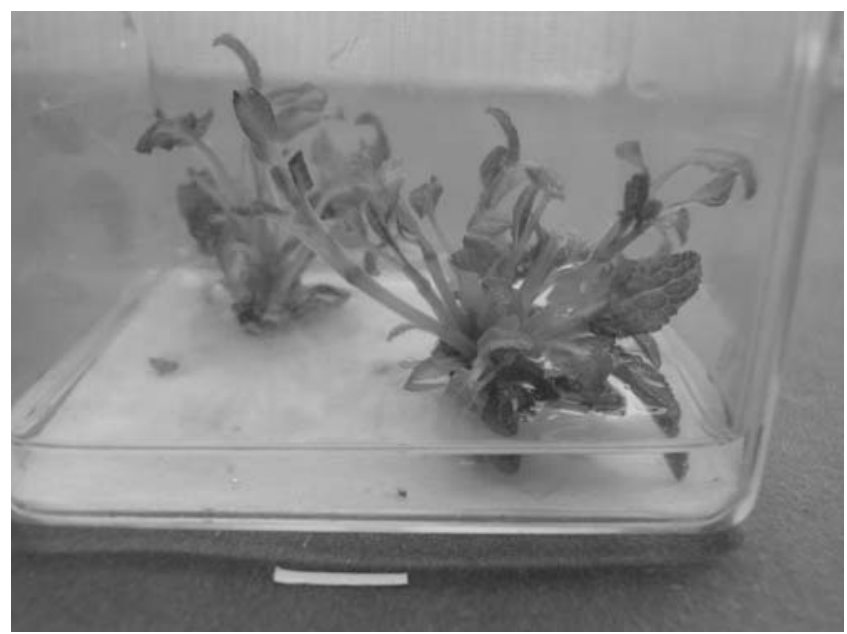

Fig. 1. Multiplied shoots of $S$. officinalis in Magenta vessel in liquid MS medium supplemented with IAA $\left(0.1 \mathrm{mg} \mathrm{l}^{-1}\right)$ and BAP $\left(0.45 \mathrm{mg} \mathrm{l}^{-1}\right)$ after 3 weeks. Bar $1 \mathrm{~cm}$.

TABLE 1. The effect of TRIA on multiplication and growth of S. officinalis shoots. The shoots grown in liquid MS medium supplemented with IAA $\left(0.1 \mathrm{mg} \mathrm{l}^{-1}\right)$ and BAP $\left(0.45 \mathrm{mg} \mathrm{l}^{-1}\right)$ for 3 weeks.

\begin{tabular}{cccc}
\hline $\begin{array}{c}\text { TRIA } \\
\left(\mathrm{\mu g} \mathrm{l}^{-1}\right)\end{array}$ & $\begin{array}{c}\text { Average shoot } \\
\text { number/explant }\end{array}$ & $\begin{array}{c}\text { Average shoot } \\
\text { length } \\
{[\mathrm{cm}]}\end{array}$ & $\begin{array}{c}\text { Mean } \\
\text { growth index }\end{array}$ \\
\hline 0 & $2.90 \pm 0.22 \mathrm{a}$ & $2.08 \pm 0.07 \mathrm{a}$ & $22.61 \pm 1.82 \mathrm{a}$ \\
5 & $5.94 \pm 0.37 \mathrm{bc}$ & $1.67 \pm 0.06 \mathrm{~b}$ & $23.17 \pm 0.27 \mathrm{a}$ \\
10 & $5.53 \pm 0.26 \mathrm{~b}$ & $1.93 \pm 0.12 \mathrm{ab}$ & $29.00 \pm 1.61 \mathrm{~b}$ \\
20 & $6.73 \pm 0.41 \mathrm{c}$ & $1.87 \pm 0.11 \mathrm{ab}$ & $25.94 \pm 0.27 \mathrm{ab}$ \\
\hline
\end{tabular}

The values are the means \pm SE. The means in the column followed by the same letter do not differ statistically at $\mathrm{p} \leq 0.05$.

rved, when the time spent by shoots in multiplication medium took no longer than 3 weeks. At this time, on average, 3 shoots per explant were formed and the multiplication rate in the following ten subcultures under the described conditions remained at the same level. Also on the agargelled medium with the same growth regulators, sage cultures responded with average number of 3 shoots per explant, but the time required for the shoot induction was longer (5 weeks) (Grzegorczyk et al. 2006). With respect to morphology, sage shoots grown in liquid medium were characterized by higher number of leaves, larger leaf areas and shorter internodes compared to those cultured on the agar-solidified medium (data not shown), and a decrease in the average shoot length in the liquid medium was observed. The average length of these shoots was $2 \mathrm{~cm}$ (Table 1), as against $2.5 \mathrm{~cm}$ in agar culture (Grzegorczyk et al. 2006). Moreover, shoots from liquid culture were difficult to root. Only, 35\% of the shoots formed roots within 4 weeks on 1/2 MS agar medium supplemented with IAA $\left(0.1 \mathrm{mg} \mathrm{l}^{-1}\right)$, whereas the percentage of shoots multiplied on agar-solidified medium was $77 \%$ (data not shown). As already mentioned, in our study, application of liquid medium was associated with decreased shoot length, and the effect can probably be responsible for the reduced rooting of the shoots. An inhibition of rooting of shoots, which were multiplied in liquid culture, has been also reported for Centaurium erythraea (Piątczak et al. 2005). When sage plantlets were transferred into the soil and grown in the greenhouse no differences were observed in growth and morphology between the plants coming from the liquid media during multiplication stage and those multiplied on the solid medium. Survival rate of the plantlets was above $93 \%$.

Application of liquid medium was associated not only with changes in sage shoot multiplication and their rooting, but also with stimulation of antioxidant substance production, such as carnosic acid, carnosol and rosmarinic acid. It was found that sage shoots grown in the liquid medium for 3 weeks accumulated $8.2 \mathrm{mg} \mathrm{g}^{-1}$ dry weight of diterpenoids (calculated as the sum of CA and Car) and $31.2 \mathrm{mg} \mathrm{g}^{-1}$ dry weight of RA (shoots untreated with TRIA - Figs 2 and 3). These values were about $60 \%$ and $250 \%$ higher than those for diterpenoids and RA, respectively, in sage shoots grown for 5 weeks on the agar-solidified medium of the same composition (Grzegorczyk et al. 2006). The differences were even more evident when our results with liquid culture were compared with those reported by Santos-Gomes et al. (2002) for sage shoot culture grown on MS agar medium supplemented with 2,4-D $\left(0.05 \mathrm{mg} \mathrm{l}^{-1}\right)$ and kinetin $\left(1.5 \mathrm{mg} \mathrm{l}^{-1}\right)$. The culture produced only about $2 \mathrm{mg}$ of diterpenoids $(\mathrm{CA}+\mathrm{Car})$ and $2.25 \mathrm{mg}$ of RA per gram dry

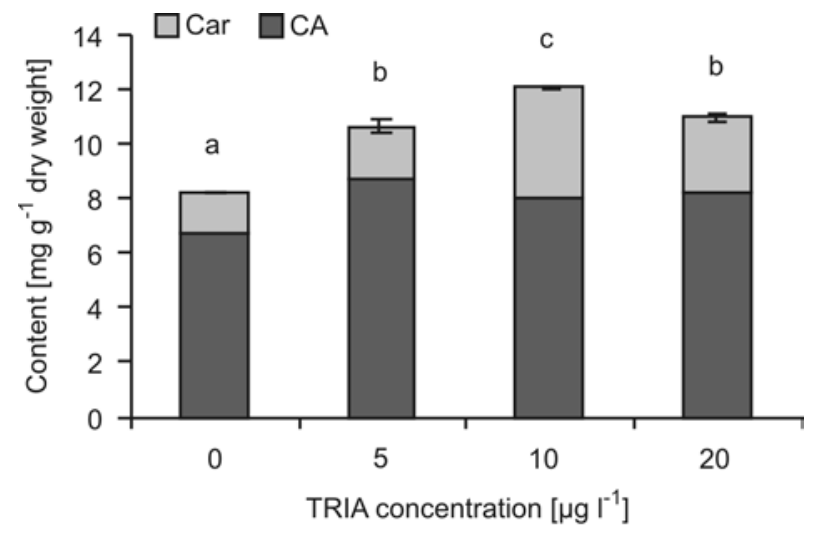

Fig. 2. The effect of TRIA on content of diterpenoids (carnosic acid and carnosol) in liquid shoot culture of $S$. officinalis. Shoots grown in liquid MS medium supplemented with IAA $\left(0.1 \mathrm{mg} \mathrm{l}^{-1}\right)$ and BAP $\left(0.45 \mathrm{mg} \mathrm{l}^{-1}\right)$ for 3 weeks.

The values are three means for sum of carnosol and carnosic acid $\pm \mathrm{SE}$. The bars with different letters indicate significant differences between treatments at $\mathrm{p} \leq 0.05$.

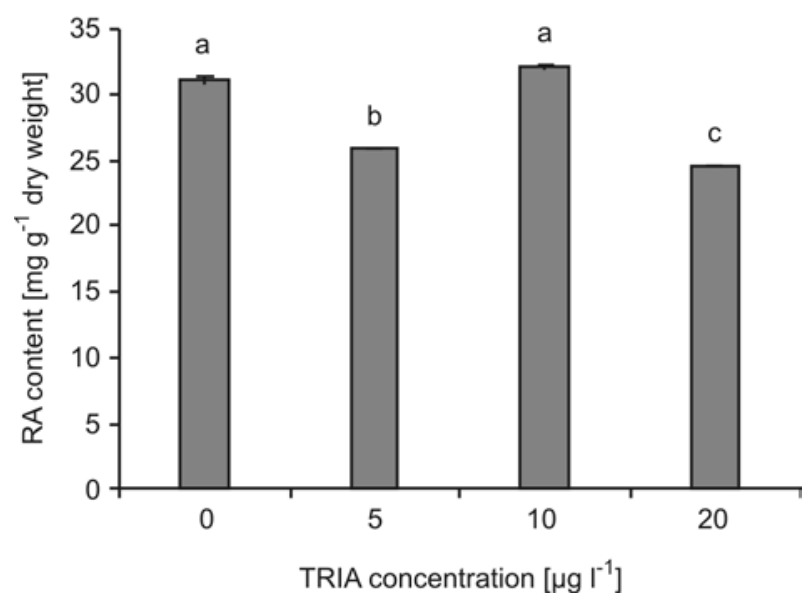

Fig 3. The effect of TRIA on content of rosmarinic acid in liquid shoot culture of $S$. officinalis. Shoots grown in liquid MS medium supplemented with IAA $\left(0.1 \mathrm{mg} \mathrm{l}^{-1}\right)$ and BAP $\left(0.45 \mathrm{mg} \mathrm{l}^{-1}\right)$ for 3 weeks.

The values are three means \pm SE. The bars with different letters indicate significant differences between treatments at $\mathrm{p} \leq 0.05$. 
weight of shoots. In this case, however, the differences in product levels could be also related to different growth regulators used in the culture. Some other plant species are also known to accumulate in liquid cultures considerable amounts of various classes of secondary metabolites. This is the case, for example with Catharanthus roseus shoot culture producing ajmalicine (Satdive et al. 2003), Stevia rebudiana in respect to steviol glycoside biosynthesis (Bondarev et al. 2002) and amphibian shoot culture of Isoptexis canariensis which accumulated cardenolides (Schaller and Kreis 2006). In the last case, however, cardenolide level was lower compared to that in the shoots cultivated on agar-solidified medium. It was also observed by Sales et al. (2002) in Digitalis minor shoot culture. The authors suggested that the reduction of cardenolide content in liquid medium might be associated with hyperhydricity of shoots grown under these conditions. It is important to notice that sage shoots were not hyperhydric when they were cultivated in liquid static culture for 3 weeks.

We studied also the effect of triacontanol on sage shoot proliferation and production of antioxidant compounds (CA, Car and RA) in liquid medium. Triacontanol, a long 30-carbon primary alcohol naturally occurring plant growth promoter is known to increase the growth and yield of some plants both in vivo and in vitro (Ries 1985; Kissimon et al. 1999; Tantos et al. 1999). We found that TRIA added to the liquid MS medium supplemented with IAA and BAP stimulated sage shoot multiplication at all concentrations tested $\left(5,10\right.$ or $\left.20 \mu \mathrm{g}^{-1}\right)$. Optimum axillary shoot induction ( 7 new shoots per explant within 3 weeks) occurred at $20 \mu \mathrm{g}^{-1}$ TRIA. Lower concentrations of TRIA ( 5 and $10 \mu \mathrm{g}^{-1}$ ) were less effective, but the number of shoots per explant was still significantly higher in comparison with the control culture (shoots untreated with TRIA) (Table 1). Also, the growth index, calculated on a fresh weight basis, was increased when TRIA was present in the liquid medium, but the shoots were slightly smaller as compared to those untreated with TRIA. The differences were not statistically significant at $20 \mu \mathrm{g}^{-1}$ TRIA, the concentration which was most responsible for shoot multiplication. TRIA was also effective for enhancement of production of antioxidant diterpenoids in sage shoots multiplied in liquid culture. The sum of CA and Car in TRIA-treatment shoots was by about $30-50 \%$ higher than in the control (significant difference at $\mathrm{p} \leq 0.05$ ). The most evident effect of triacontanol was observed on carnosol content. The amount of the oxidized derivative of carnosic acid in sage shoots grown in the presence of TRIA was even twice higher than that in control culture (Fig. 2). The results presented here are generally in agreement with data earlier obtained for solid culture of sage shoots (Grzegorczyk et al. 2006), although a difference in optimum concentration of TRIA was evident with two different culture systems. Liquid culture system exhibited maximum level of diterpenoids (12 $\mathrm{mg} \mathrm{g}^{-1}$ dry wt) with $10 \mu \mathrm{g} \mathrm{l}^{-1}$ TRIA (Fig. 2.), while $5 \mu \mathrm{g} \mathrm{l}^{-1}$ TRIA yielded a maximum CA and Car (10.2 $\mathrm{mg} \mathrm{g}^{-1}$ dry wt) in shoots grown in solid culture (Grzegorczyk et al. 2006). The fact that liquid culture requires higher concentration of TRIA for improvement of both shoot multiplication and diterpenoid accumulation suggests that the compound may be more rapidly metabolized in liquid culture than in solid medium. Moreover, significant differences in TRIA response with respect to RA production between two types of sage shoot cultures were observed. We found that TRIA had no effect on RA content (at the concentration of 10 $\mu \mathrm{g}^{-1}$ ) or slightly reduced its level (at 5 or $20 \mu \mathrm{g} \mathrm{l}^{-1}$ ) in sage shoots cultured in the liquid medium, although the growth regulator had been increased the RA level in the solid culture at all used concentrations $\left(5,10\right.$ or $\left.20 \mu \mathrm{g} \mathrm{l}^{-1}\right)$. In literature only the increase in essential oil yields in micropropagated plantlets of Thymus mastichina (Fraternale et al. 2003) and Artemisia annua in vitro culture (Yaseen and Tajuddin 1998) have been described as the result of TRIA treatment. The effect of TRIA on other secondary metabolites has not been still reported. Also the mechanism action of triacontanol on secondary metabolite production has remained unknown.

Taking together the results of the current study and those obtained earlier (Grzegorczyk et al. 2006), it is evident that the type of medium (liquid/solid) affects shoot multiplication, their quality and production of secondary metabolites in sage culture. The negative effect of liquid culture on shoot rooting is a significant problem in the wide use of the culture for micropropagation of $S$. officinalis. On the other hand, liquid shoot culture could be useful for the production of antioxidant compounds. The amounts of carnosol and carnosic acid in shoots grown in the liquid medium were comparable to these of two commercially available samples of sage leaves. The latter plant material, however, contained up to 24 times less RA found in liquid culture of sage shoots (Table 2). It is known that aerial parts, especially leaves, of sage and rosemary plants are the main site of accumulation of CA and Car (Munne-Bosch and Alegre 2001). Only the trace amount of the compounds was detected in roots of the plants (Munne-Bosch and Alegre 2001). Here, we analyzed the contents of CA, Car and RA in different parts of shoots of 10-week-old micropropagated plants of S. officinalis in order to check the distribution of antioxidant compounds within the shoots. As can be seen in Table 3, the youngest, upper parts of shoots, consisting of the terminal bud and two nodes below the bud with two pairs of leaves, had considerably higher levels of both di-

TABLE 2. Content of carnosol, carnosic acid and rosmarinic acid in commercially available samples of $S$. officinalis dried leaves.

\begin{tabular}{lccc}
\hline & \multicolumn{3}{c}{ Content $\left[\mathrm{mg} \mathrm{g}^{-1}\right.$ dry wt $]$} \\
\cline { 2 - 4 } Sample from & CA & Car & RA \\
\cline { 2 - 4 } Kawon & $8.35 \pm 0.10$ & $1.46 \pm 0.07$ & $1.31 \pm 0.03$ \\
Phytopharm & $9.47 \pm 0.09$ & $2.45 \pm 0.01$ & $7.30 \pm 0.14$ \\
\hline
\end{tabular}

The values are the means \pm SE of three replicates.

TABLE 3. Comparison of CA, Car and RA contents [mg g ${ }^{-1}$ dry wt] in different parts of shoots of 10 -week-old micropropagated $S$. officinalis plants grown in greenhouse.

\begin{tabular}{cccc}
\hline & \multicolumn{3}{c}{ Content $\left[\mathrm{mg} \mathrm{g}^{-1}\right.$ dry wt $]$} \\
\cline { 2 - 4 } Plant material & CA & Car & RA \\
\cline { 2 - 4 } & $11.37 \pm 0.16$ & $1.09 \pm 0.08$ & $12.23 \pm 0.17$ \\
\hline Whole shoots & & & $15.00 \pm 0.18$ \\
Shoot part & $23.13 \pm 0.40$ & $2.09 \pm 0.20$ & $10.57 \pm 0.23$ \\
upper & $12.49 \pm 0.31$ & $0.92 \pm 0.03$ & $10.99 \pm 0.08$ \\
inner & $4.39 \pm 0.07$ & $0.54 \pm 0.05$ &
\end{tabular}

The values are the means $\pm \mathrm{SE}$ of three replicates. 
terpenoids and RA than the remaining, older parts of shoots. The result indicates that the position of the leaves on sage shoot should be taken into consideration when sage plant material has been chosen for extraction of antioxidant compounds. The results are in accordance with Hidalgo et al. (1998), who also found that the content of carnosic acid is the highest in youngest leaves of Rosmarinus officinalis. The authors suggested that it might be due to the fact that antioxidants as protective compounds are important at the early growth stage, where young leaves are more vulnerable and/or young leaves have a far more active metabolism, so they require higher concentrations of essential compounds needed for growing. Our sage shoot culture started from shoot tips and grown under optimum conditions (i.e. MS liquid medium supplemented with $0.1 \mathrm{mg} \mathrm{l}^{-1}$ IAA, 0.45 $\mathrm{mg}^{-1}$ BAP and $20 \mu \mathrm{g} \mathrm{l}^{-1}$ TRIA) contained about $50 \%$ of the diterpenoids $(\mathrm{CA}+\mathrm{Car})$ accumulated in the top parts of shoots of micropropagated plants grown for 10 weeks in the greenhouse conditions. However, considering the time which is needed to accumulate diterpenoids in liquid shoot culture (3 weeks), accumulation is nearly comparable. It should be also noticed that liquid shoot culture represents advancement in respect to RA accumulation; content of the depside in shoots grown in liquid culture was over two fold higher than that in young, upper parts of sage shoots (Table 3).

This is the first study concerning production of CA, Car and RA in sage shoots grown in liquid medium. The system may be important for further investigations focused on the production of the antioxidant metabolites in sage shoots grown in a bioreactor. Based on these results the bioreactor model in which shoots would be temporarily immersed in the liquid medium is proposed.

\section{ACKNOWLEDGEMENTS}

This work was supported by grant 092/P05/2003.

\section{LITERATURE CITED}

ASCOUGH G.D., FENNELL C.W. 2004. The regulation of plant growth and development in liquid culture. S. Afr. J. Bot. 70: 181-190.

BARICEVIC D., SOSA S., DELLA LOGGIA R., TUBARO A., SIMONOVSKA B., KRASNA A., ZUPANCIC A. 2001. Topical anti-inflammatory activity of Salvia officinalis L. leaves: the relevance of ursolic acid. J. Ethnopharmacol. 75: 125-132.

BONDAREV N., RESHETNYAK O., NOSOV A. 2002. Features of development of Stevia rebaudiana shoots cultivated in the roller bioreactor and their production of steviol glycosides. Planta Med. 68: 759-762.

CUVELIER M.E., BERSET C., RICHARD H. 1994. Antioxidant constituents in sage (S. officinalis). J. Agric. Food Chem. 42: 665-669.

DEBERGH P.C. 1983. Effects of agar brand and concentration on the tissue culture medium. Physiol. Plant. 59: 270-276.

ESSWAY G.S., SOBBHY H.M., BANNA H.A. 1995. The hypoglycemic effect of volatile oil of some Egyptian plants. Vet. Med. J. 43: 167-172.

FARAG R.S., DAW Z.Y., HEWEDI F.M., EL-BAROTY G.S.A. 1989. Antimicrobial activity of some Egyptian spice oils. J. Food Prot. 52: 665-667.

FRATERNALE D., GIAMPERI L., RICCI D., ROCCHI M.B.L., GUIDI L., EPIFANO F. 2003. The effect of triacontanol on micropropagation and on secretary system of Thymus mastichina. Plant Cell Tiss. Org. Cult. 74: 87-97.
GRZEGORCZYK I., WYSOKIŃSKA H. 2004. Mikrorozmnażanie Salvia officinalis L. z wierzchołków pędów. Biotechnologia 65: 212-218. (in Polish with English summary)

GRZEGORCZYK I., BILICHOWSKI I., MIKICIUK-OLASIK E., WYSOKIŃSKA H. 2005. In vitro cultures of Salvia officinalis L. as a source of antioxidant compounds. Acta Soc. Bot. Pol. 74: 17-21.

GRZEGORCZYK I., BILICHOWSKI I., MIKICIUK-OLASIK E., WYSOKIŃSKA H. 2006. The effect of triacontanol on shoot multiplication and production of antioxidant compounds in shoot cultures of Salvia officinalis L. Acta Soc. Bot. Pol. 75: $11-15$.

HARAGUCHI H., SAITO T., OKAMURA N., YAGI A. 1995. Inhibition of lipid peroxidation and superoxide generation by diterpenoids from Rosmarinus officinalis. Planta Med. 61: 333-336.

HIDALGO P.J., UBERA J.L., TENA M.T., VALCÁRCEL M. 1998. Determination of the carnosic acid contents in wild and cultivated Rosmarinus officinalis. J. Agric. Food Chem. 46: 2624-2627.

HUANG M.T., HO C.T., WENG Z.X., FERRERO T., LOU Y.R., STANBER K., MA W., GEORGIADIS C., LASHIN J.D., CONNEY A. 1994. Inhibition of skin tumorigenesis by rosemary and its constituents carnosol and ursolic acid. Cancer Res. 54: 701-708.

KISSIMON J., TANTOS A., MESZAROS A., JAMBOR-BENCZUR E., HORVATH G. 1999. Stress alternation in growth parameters, pigment content and photosynthetic function of in vitro cultured plants. Z. Naturforsch. 54c: 834-839.

LEUNG A.Y. 1989. Cosmetics made from Chinese herb extracts. Drug and Cosmetic Industry. April: 35-40.

MUNNE-BOSCH S., ALEGRE L. 2001. Subcellular compartmentation of the diterpene carnosic acid and its derivatives in the leaves of rosemary. Plant Physiol. 125: 1094-1102.

MURASHIGE T., SKOOG F. 1962. A revised medium for rapid growth and bioassays with tobacco tissue cultures. Physiol. Plant. 15: 473-497.

OFFORD E.A., MACE K., RUFFIEUX C., MALONE A., PFEIFER A.M. 1995. Rosemary components inhibit benzo[a]pyrene-induced genotoxicity in human bronchial cells. Carcinogenesis, 16: 2057-2062.

OLSZOWSKA M., FURMANOWA M. 1990. Micropropagation of Salvia officinalis by shoot buds. Planta Med., 56, 637.

PIĄTCZAK E., WIELANEK M., WYSOKIŃSKA H. 2005. Liquid culture system for shoot multiplication and secoiridoid production in micropropagated plants of Centaurium erythraea Rafn. Plant Sci. 168: 431-437.

RAU O., WURGLICS M., PAULKE A., ZITZKOWSKI J., MEINDL N., BOCK A., DINGERMANN T., ABDEL-TAWAB M., SCHUBERT-ZSILAVECZ M. 2006. Carnosic acid and carnosol, phenolic diterpene compounds of the labiate herbs rosemary and sage, are activators of the human peroxisome proliferators-activated receptor gamma. Planta Med. 72: 881-887.

RIES S.K. 1985. Regulation of plant growth with triacontanol. CRC Crit. Rev. Plant Sci. 2: 239-285.

SALES E., NEBAUER S.G., ARRILAGA I., SEGURA J. 2002. Plant hormones and Agrobacterium tumefaciens strain 82139 induce efficient plant regeneration in the cardenolide - producing plant Digitalis minor. J. Plant Physiol. 159: 9-16.

SANTOS-GOMES P.C., SEABRA R.M., ANDRADE P.B., FERNANDES-FERREIRA M. 2002. Phenolic antioxidant compounds produced by in vitro shoots of sage (Salvia officinalis L.). Plant Sci. 62: 981-987.

SATDIVE R.K., FULZELE D.P., EAPEN S. 2003. Studies on production of ajmalicine in shake flasks by multiple shoot culture of Catharanthus roseus. Biotechnol. Prog. 19: 1071-1075.

SCHALLER F., KREIS W. 2006. Cardenolide geninpattern in Isoplexis plants and shoot cultures. Planta Med. 72: 1149$-1156$. 
TADA M., OKUNO K., CHIBA K., OHNISHI E., YOSHII T. 1994. Antiviral diterpenes from Salvia officinalis. Phytochemistry, 35: 539-541.

TANTOS A., MESZAROS A., KISSIMON J., HORVATH G., FARKAS T. 1999. The effect of triacontanol on micropropagation of balm, Melissa officinalis L. Plant Cell Rep. 19: 88-91.
YASEEN M., TAJUDDIN K. 1998. Effect of plant growth regulators on yield, oil composition and artemisina of Artemisa anпиа under temperature conditions. J. Med. Aromat. Plant Sci. 20: 1038-1041.

ZIV A., HALEVY A.H. 1983. Control of oxidative browning and in vitro propagation of Strelitzia reginae. Hort. Sci. 18: 434-436. 